\title{
WN4 effect on longitudinal distribution of different ion species in the topside ionosphere at low latitudes by means of DEMETER, DMSP-F13 and DMSP-F15 data
}

\author{
L. Bankov ${ }^{1}$, R. Heelis ${ }^{2}$, M. Parrot ${ }^{3}$, J.-J. Berthelier ${ }^{4}$, P. Marinov ${ }^{5}$, and A. Vassileva ${ }^{1}$ \\ ${ }^{1}$ Space Research Institute at the Bulgarian Academy of sciences, 6 Moskovska str., Sofia 1000, Bulgaria \\ ${ }^{2}$ W. B. Hanson Center for Space Science, University of Texas at Dallas, Richardson, TX 075080, USA \\ ${ }^{3}$ Laboratoire de Physique et Chimie de l'Environnment, CNRS, 45071Orleans-CEDEX, France \\ ${ }^{4}$ CETP/IPSL, 4 avenue de Neptune, 94100 SAINT-MAUR, France \\ ${ }^{5}$ Institute of Parallel Processing-BAS, Acad. G. Bonchev, str. B1. 25a, Bulgaria
}

Received: 1 October 2008 - Revised: 25 February 2009 - Accepted: 14 July 2009 - Published: 22 July 2009

\begin{abstract}
Plasma probe data from DMSP-F13, DMSP-F15 and DEMETER satellites were used to examine longitudinal structures in the topside equatorial ionosphere during fall equinox conditions of 2004 year. Since the launch of DEMETER satellite on 29 June 2004, all these satellites operate close together in the topside ionosphere. Here, data taken from Special Sensor-Ion, Electron and Scintillations (SSIES) instruments on board DMSP-F13, F15 and Instrument Analyser de Plasma (IAP) on DEMETER, are used. Longitudinal variations in the major ions at two altitudes $(\sim 730 \mathrm{~km}$ for DEMETER and $\sim 840 \mathrm{~km}$ for DMSP) are studied to further describe the recently observed "wavenumber-four" (WN4) structures in the equatorial topside ionosphere. Different ion species $\mathrm{H}^{+}, \mathrm{He}^{+}$and $\mathrm{O}^{+}$have a rather complex longitudinal behavior. It is shown that WN4 is almost a regular feature in $\mathrm{O}^{+}$the density distribution over all local times covered by these satellites. In the evening local time sector, $\mathrm{H}^{+}$ions follow the $\mathrm{O}^{+}$behavior within WN4 structures up to the premidnight hours. Near sunrise $\mathrm{H}^{+}$and later in the daytime, $\mathrm{He}^{+}$longitudinal variations are out of phase with respect to $\mathrm{O}^{+}$ions and effectively reduce the effect of $\mathrm{WN} 4$ on total ion density distribution at altitudes $730-840 \mathrm{~km}$. It is shown that both a WN4 $\boldsymbol{E} \times \boldsymbol{B}$ drift driver and local F-region winds must be considered to explain the observed ion composition variations.
\end{abstract}

Keywords. Ionosphere (Equatorial ionosphere)

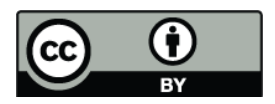

Correspondence to: L. Bankov (lbankov@space.bas.bg)

\section{Introduction}

Longitudinal variations in the equatorial ionospheric anomaly (EIA) have been intensively studied following recent observations of wavenumber-four structures in the nighttime OI135.6-nm emission along the geomagnetic equator by the Far Ultraviolet (FUV) and Global Ultraviolet Imager (GUVI) instruments on board the IMAGE and TIMED satellites (Sagawa et al., 2005; Henderson et al., 2005). Four longitudinal peaks in $135.6-\mathrm{nm}$ brightness observed on both sides of the geomagnetic equator were found to be in near coincidence with four tidal maxima in atmospheric temperature at $115 \mathrm{~km}$ altitude predicted from the Global Scale Wave Model (GSWM) (Immel et al., 2006). It is suggested that these observations result from upward propagating atmospheric tides reaching E-region heights, and modifying the dynamo electric field to produce four longitudinal peaks in the equatorial fountain effect (Immel et al., 2006; Hagan et al., 2007; Pedatella et al., 2008).

In support to this assumption, longitudinal variations in the noontime current density in the equatorial electrojet derived from CHAMP, Ørsted and SAC-C magnetometer data, show the same WN4 structures with apparent horizontal scale $10000 \mathrm{~km}$ in the satellite frame of reference (England et al., 2006; Lühr et al., 2008). Total electron content (TEC) data from occultation experiments on board COSMIC/Formosat3 satellite constellation offered an opportunity to estimate the vertical extent of WN4 longitudinal structures (Lin et al., 2007). It was found that the largest amplitude WN4 variations in the electron density appear between 12:00 16:00 LT, at the crests of the EIA. TEC data from JPL Global

Published by Copernicus Publications on behalf of the European Geosciences Union. 
Ionospheric Maps (Wan et al., 2008) and TOPEX satellite (Scherliess et al., 2008) have also been used to examine diurnal, seasonal and solar cycle effects on WN4 variations. Both data sets show that WN4 is a longitudinal feature in TEC with four, almost equally spaced peaks in electron density on both sides of the geomagnetic equator. It is seen throughout the daytime and can be recognized up to midnight. Diurnal variations in the peak longitudes show an average speed of $90^{\circ}$ per day eastward drift, smaller in daytime and larger at night (Wan et al., 2008). Such an eastward motion of peaks is attributed to the combined effect of the eastward drifting DE3 tidal mode and diurnal variations of zonal ion drift, negative at daytime and positive at night (Fejer et al., 1991). The largest amplitude WN4 variations in TEC appear during equinox and summer months, the variations being relatively weaker or absent in winter months. No significant dependencies on solar cycle have been reported (Scherliess et al., 2008; Wan et al., 2008).

WN4 signatures in vertical ion drift velocity near the magnetic equator, first reported from in situ observations by DMSP-F15 (Hartman and Heelis, 2007) and ROCSAT-1 (Kil et al., 2007), appear to support the proposed physical mechanism for WN4 variations in F-peak ion density (Immel et al., 2006). During the daytime topside ionosphere WN4 peaks in vertical ion drift velocity appear collocated with longitudinal maximums in ion density (Kil et al., 2008). The longitudinal distribution of total ion density $\mathrm{Ni}$ and electron temperature Te, taken near the geomagnetic equator show clear WN4 variations during equinox and summer months from DMSPF13 daytime observations (Ren et al., 2008).

At mid and low latitudes the topside F-region plasma has remarkable longitudinal variations in $\mathrm{H}^{+}, \mathrm{He}^{+}$and $\mathrm{O}^{+}$densities (West and Heelis, 1996; Su et al., 2005). The distribution of ionospheric plasma density and temperature along the magnetic field in the topside F-region strongly depends on both, field aligned motion and $\boldsymbol{E} \times \boldsymbol{B}$ drift of ions (Rishbeth, 2000; Heelis, 2004). In general, $\boldsymbol{E} \times \boldsymbol{B}$ motion creates latitudinally symmetric strictures with respect to the geomagnetic equator. Therefore, it could be expected that a tidal influence of vertical $\boldsymbol{E} \times \boldsymbol{B}$ drift on the topside F-region will cause symmetric effects on the different ionospheric plasma constituents on both sides of geomagnetic equator. However, in the case of imbalanced meridional components of neutral wind on both sides of magnetic equator, induced field aligned motion of ions will cause asymmetries in the plasma density and temperature distribution along the magnetic equator (MacPherson et al., 1998; Bailey et al., 2000). It was shown by (Bailey and Heelis, 1980), that F-region meridional winds of $100 \mathrm{~m} / \mathrm{s}$ can cause $300 \mathrm{~m} / \mathrm{s}$ interhemispheric velocities at the apex of field lines near $1000 \mathrm{~km}$ altitude. The effects of geographic zonal and meridional neutral wind components on plasma distributions along the magnetic field strongly depends on magnetic declination (West and Heelis, 1996; Bailey et al., 2000; Su et al., 2005; Kil et al., 2006). Thus, longitudinally dependent field-aligned plasma motions may be combined with the WN4 induced $\boldsymbol{E} \times \boldsymbol{B}$ drift motions in any set of observations.

In this work we examine the longitudinal and latitudinal variations of major ion species in the topside ionosphere using DMSP-F13, F15 and DEMETER data taken near $840 \mathrm{~km}$ and $730 \mathrm{~km}$ altitude. Previous studies have shown that WN4 tidal effects in neutral temperature and zonal wind at Eregion heights have a maximum in autumnal equinox months (Oberheide and Forbes, 2008). Thus we confine our study to the fall equinox in 2004 and use the variations in the constituent ion densities to examine the contributions of $\boldsymbol{E} \times \boldsymbol{B}$ drifts and neutral winds.

\section{Experimental results}

\subsection{The data set}

The Defense Meteorological Satellite Program, DMSP-F13 and DMSP-F15 satellites have been in operation since 1994 and 1999, respectively. Both satellites are launched onto near circular Sun synchronous orbit (SSO) with $98^{\circ}$ inclination at $\sim 840 \mathrm{~km}$ height with ascending node local times of $\sim$ 17:45 LT(F13) and $\sim 21: 30 \mathrm{LT}(\mathrm{F} 15)$. The payload includes a planar Retarding Potential Analyzer (RPA) which provides the ion density $\mathrm{Ni}$, ion mass $\mathrm{Mi}$, ion temperature $\mathrm{Ti}$ and ram ion drift velocity with a $4 \mathrm{~s}$ time step along the satellite orbit (http://cindispace.utdallas.edu/DMSP). The French microsatellite DEMETER (Detection of Electro-Magnetic Emissions Transmitted from Earthquake Regions) was launched on 29 June 2004 onto circular SSO with $98^{\circ}$ inclination and $710-730 \mathrm{~km}$ initial height (Cussac et al., 2006). Local time of the ascending node is $\sim 22: 30$ LT. On board thermal plasma diagnostics include IAP instrument, which provides essentially the same data as the SSIES with $4.32 \mathrm{~s}$ time step along the orbit (http://demeter.cnrs-orleans.fr/).

Here, RPA data output for $\mathrm{H}^{+}, \mathrm{He}^{+}$and $\mathrm{O}^{+}$densities from both SSIES and IAP instruments are used. It is important to note, that mass-spectrometric capabilities of the RPA sensor are significantly improved over earlier experiments on board satellites and rockets (Hanson et al., 1964; Knudsen, 1966; Hanson et al., 1970; Chandra, 1970). A detailed description of the RPA measuring technics relevant to it in situ satellite application on board DMSP and DEMETER is given in (Hanson and Heelis, 1975; Heelis and Hanson, 1998; Berthelier et al., 2006).

During the solar minimum conditions of 2004, both $\mathrm{H}^{+}$ and $\mathrm{O}^{+}$ions become dominant at the orbital height of DMSP and DEMETER satellites at different local times. Generally, $\mathrm{He}^{+}$is a small fraction of the total density at almost all longitudes at the DMSP orbital altitude.The RPA measures the total ion density in the range $10^{3}$ to $10^{6} \mathrm{~cm}^{-3}$ with a precision of $1 \%$. At $730 \mathrm{~km}$ the $\mathrm{He}^{+}$can exceed the $\mathrm{H}^{+}$density. Whenever $\mathrm{H}^{+}$and $\mathrm{He}^{+}$densities reach a $5 \%$ of total $\mathrm{Ni}$, they can be recognized and retrieved from the analysis procedures 


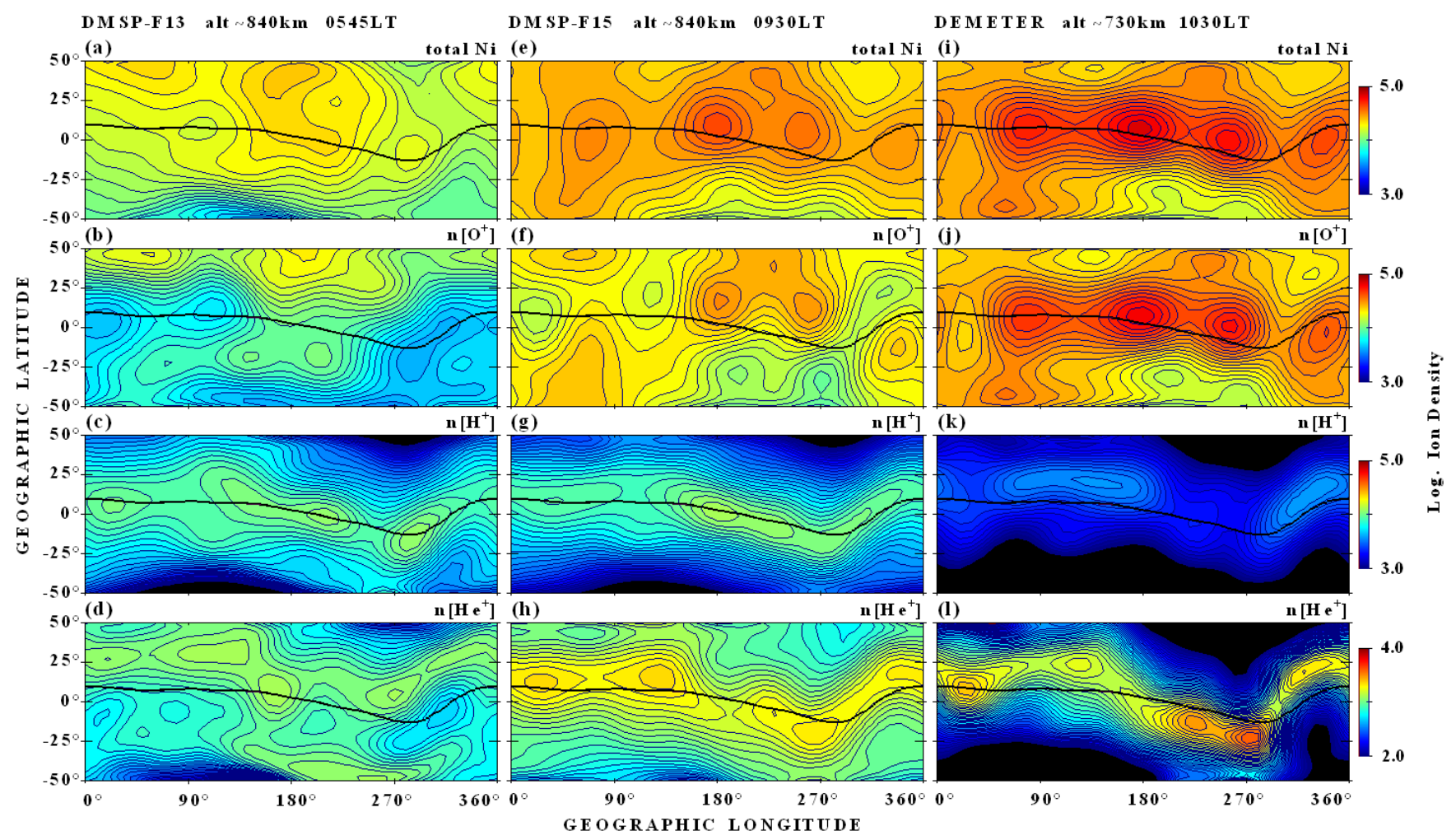

Fig. 1. Morning ion density variations from RPA onboard DMSP-F13, DMSP-F15 and DEMETER (left to the right), presented in isodensity maps from $\pm 50^{\circ}$ geographic latitude vs. $0^{\circ} \div 360^{\circ}$ geographic longitude. From top to the bottom of each column, four panels of total ion density $\mathrm{Ni}, n\left[\mathrm{O}^{+}\right], n\left[\mathrm{H}^{+}\right]$and $n\left[\mathrm{He}^{+}\right]$variations, are shown. The solid black line depicts the location of the geomagnetic equator. Thin black contours correspond to 50 density levels of logarithmic color bar given at the right side of figure.

(Hanson and Heelis, 1975; Heelis and Hanson, 1998; Su et al., 2005; Berthelier et al., 2006).

In this paper, we examine longitudinal variations in total $\mathrm{Ni}, \mathrm{H}^{+}, \mathrm{He}^{+}$and $\mathrm{O}^{+}$densities using data from RPA instruments on board DMSP-F13, F15 and DEMETER. The data used are selected to represent relatively low geomagnetic activity levels $\left(0>D_{s t}>-50\right)$ and $F_{10.7}<130$ within 60 days from 20 August to 20 October 2004. The average solar radio flux for the period is $F_{10.7}=98.4$. For the purpose of this study, ion composition data have been averaged in 36 bins of geographic longitude from $0^{\circ}$ to $360^{\circ}$ and 40 bins in geographic latitude from $-50^{\circ}$ to $50^{\circ}$. This data is then represented by a discrete fourier series containing the first 6 periods in longitude and by a 7-th order Chebyshev polynomial in latitude.

\subsection{WN4 influence on the morning morphology of top- side $\mathrm{Ni}, \mathrm{H}^{+}, \mathrm{He}^{+}$and $\mathrm{O}^{+}$ions}

Figure 1 shows in three separate columns, geographic latitude vs. longitude iso-density maps of total $\mathrm{Ni}, \mathrm{H}^{+}, \mathrm{He}^{+}$ and $\mathrm{O}^{+}$concentrations derived from DMSP-F13, F15 and DEMETER shown. On top of each column, the satellite, altitude and local time of the observations are identified. The orbit inclination produces a local time difference of about one hour between the northern (top) and southern (bottom) extents of each plot. On the upper right corner of each panel the plasma parameter is given. The color scale denotes the logarithm of the number density, while the black trace through the displays denotes the position of the geomagnetic equator. Note that the same color scale represents $\mathrm{He}^{+}$number densities that are smaller by a factor of 10 .

The total ion density distribution near $840 \mathrm{~km}$ and 05:45 LT in Fig. 1a, shows weak longitudinal variations. A broad maximum across the magnetic equator and into northern latitudes in the region of positive magnetic declination from $120^{\circ}$ to $260^{\circ}$ geographic longitudes is the most conspicuous feature. A weak minimum across the equator and extending to southern latitudes is seen in the region of positive magnetic declination from $300^{\circ}$ to $360^{\circ}$ geographic longitude. The $\mathrm{O}^{+}$and $\mathrm{H}^{+}$density distributions in Fig. $1 \mathrm{~b}$ and $\mathrm{c}$ are also most strongly influenced by magnetic declination but a weak WN4 behavior is also seen with local maxima in $\mathrm{H}^{+}$density at the equator collocated with local minima in the $\mathrm{O}^{+}$density.

At this local time, $\mathrm{He}^{+}$density remains near or less that $5 \%$ of the total density and no meaningful features can be recognized. Significant WN4 signatures appear later, after 


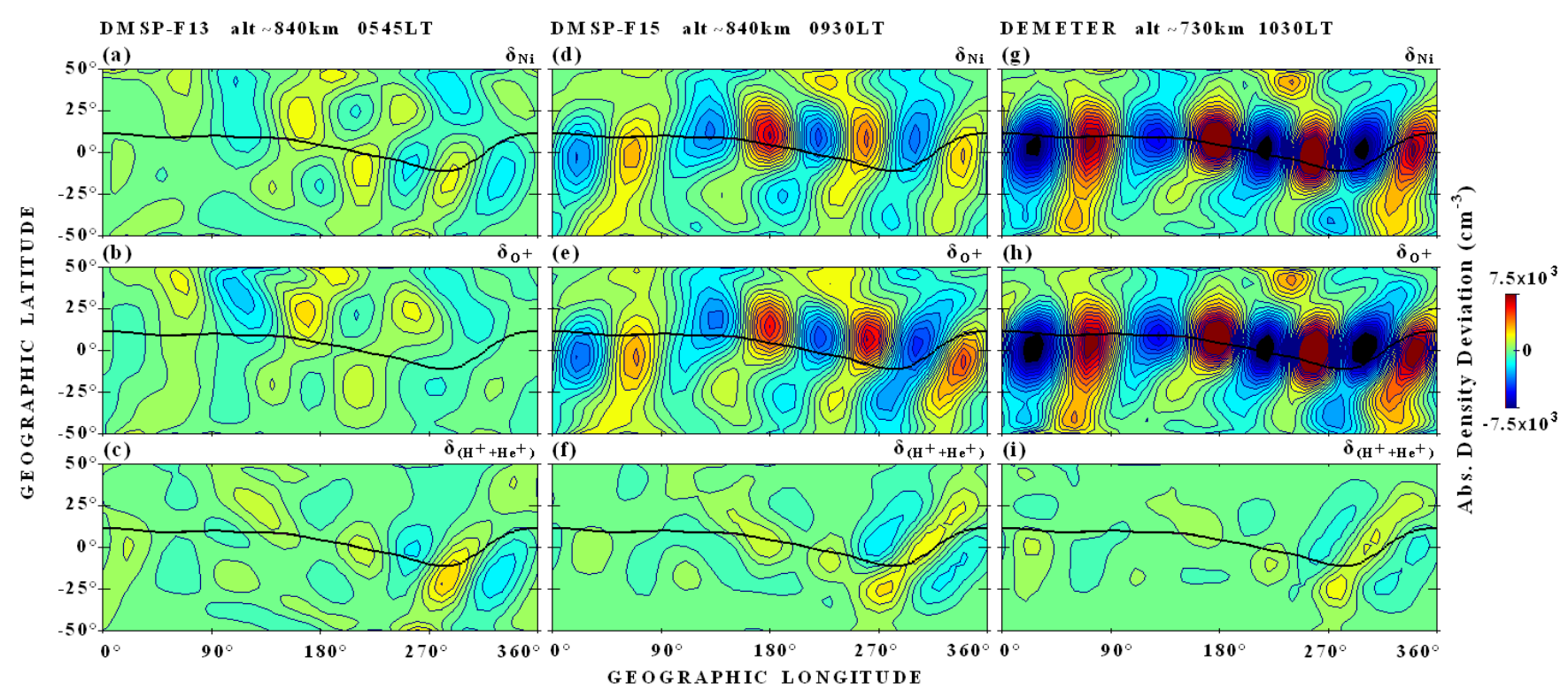

Fig. 2. Morning WN4 density deviation maps from DMSP-F13, DMSP-F15 and DEMETER (left to the right) within $\pm 50^{\circ}$ geographic latitude vs. $0^{\circ} \div 360^{\circ}$ geographic longitude, are shown. From top to the bottom of each column, $\delta \mathrm{Ni} \delta \mathrm{O}^{+}$and $\delta\left(\mathrm{H}^{+}+\mathrm{He}^{+}\right)$variations are given. Thin black contours of 25 deviation levels correspond to the linear color bar given at the right side, within the range $-7.5 \times 10^{3} \mathrm{~cm}^{-3}$ to $7.5 \times 10^{3} \mathrm{~cm}^{-3}$.

sunrise at 09:30 LT in the F15 density plots shown in the central column (Fig. 1e-h). Three local maxima in the $\mathrm{O}^{+}$ density are displaced northward of the magnetic equator in the longitude range $0^{\circ}$ to $270^{\circ}$ where the magnetic declination is zero and positive. One local maximum is located southward of the magnetic equator in the longitude region $300^{\circ}$ to $360^{\circ}$ where the magnetic declination is negative. In most cases the displaced maxima are accompanied by local minima in the adjacent hemisphere. The $\mathrm{H}^{+}$density is very low at this local time and altitude and no significant longitude structure can be seen at the magnetic equator. However, at lower density levels (Fig. 1h), $\mathrm{He}^{+}$ions reveal some evidence for a WN4 longitudinal distribution, which peaks at the equator that appear to be anti-correlated with the peaks in $\mathrm{O}^{+}$density.

One hour later in local time (Fig. 11), at the lower altitude of the DEMETER satellite $(\sim 730 \mathrm{~km})$, the same WN4 longitudinal behavior in $\mathrm{Ni}$ and $\mathrm{O}^{+}$can be recognized at higher density levels with the peaks closer to the magnetic equator. At this lower altitude the $\mathrm{H}^{+}$density is much lower and longitude variations at the magnetic equator cannot be identified with confidence. At $730 \mathrm{~km}$ altitude, the $\mathrm{He}^{+}$density maxima are situated slightly further from geomagnetic equator compared to their position at $840 \mathrm{~km}$ height consistent with the distribution along the magnetic field lines.

To recognize effectively WN4 structures in the ion density from DMSP and DEMETER data, we remove density variations with larger scales. First, the data are smoothed longitudinally using a running mean with length of nine data points (90 degrees in longitude). Absolute density deviations $\delta \mathrm{N}$ calculated as $\delta \mathrm{N}=(\mathrm{N}-\mathrm{Nsmooth})$ are used here to the principal WN4 wave in data. The relative contribution of $\mathrm{He}^{+}$to the WN4 wave amplitude, in most of the cases remains smaller that those of $\mathrm{Ni}, \mathrm{O}^{+}$and $\mathrm{H}^{+}$. Thus, $\delta \mathrm{N}$ values for light ion density collectively sum the contributions from $\mathrm{H}^{+}$and $\mathrm{He}^{+}$. Figure 2 shows the morning wave-like variations, shown in the same geographical frame of reference already used on Fig. 1. Vertical columns for F13, F15 and DEMETER represent longitude vs. latitude behavior of the total density, the $\mathrm{O}^{+}$density and the light ion density $\left(\mathrm{H}^{+}+\mathrm{He}^{+}\right)$. To the right a color scale shows the range of absolute density deviations.

Panel (a) of Fig. 2 (05:45 LT), shows that in the early morning hours a WN4 structure is extremely weak. However, toward daytime WN4 structures are quite well defined in the total density and $\mathrm{O}^{+}$density (panels d and e) on Fig. 2 for 09:30 LT from F15 data and become more prominent at later local times and lower altitudes (panels $g$ and $h$ ). Throughout the region of positive declination, peaks lie northward of geomagnetic equator and in the negative declination zone a southward shift is seen. The shifts are much smaller at the lower altitude of DEMETER. From bottom panels of Fig. 2, wave-like structures in the much lower density light ions are extremely weak in the morning hours.

\subsection{WN4 influence on the evening morphology of top- side $\mathrm{Ni}, \mathrm{H}^{+}, \mathrm{He}^{+}$and $\mathrm{O}^{+}$ions}

The evening distribution of $\mathrm{Ni}, \mathrm{n}\left[\mathrm{O}^{+}\right], \mathrm{n}\left[\mathrm{H}^{+}\right]$and $\mathrm{n}\left[\mathrm{He}^{+}\right]$ is shown on Fig. 3 in the same format as Fig. 1. From left to right columns in Fig. 3, reveal significant WN4 structures 


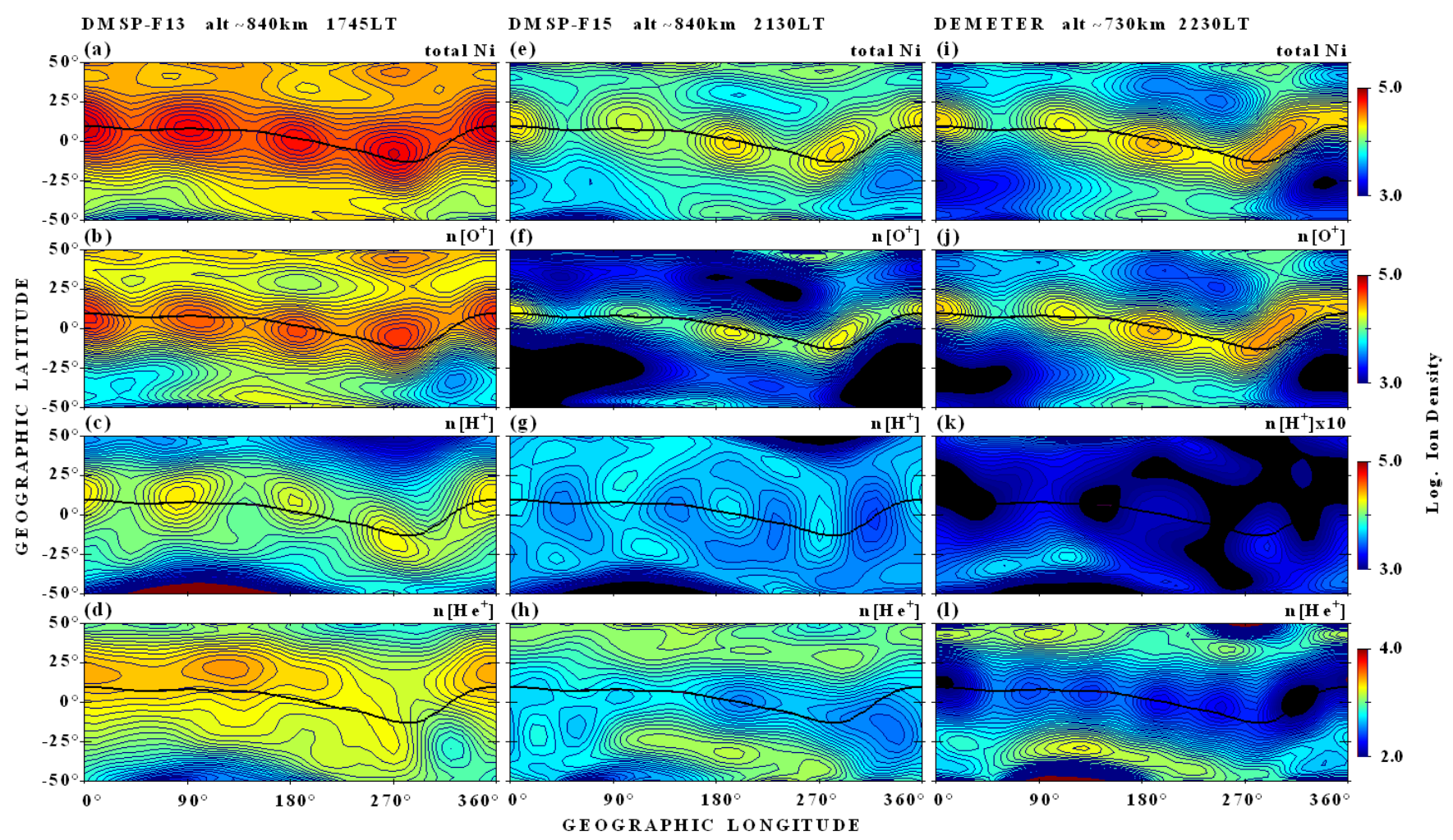

Fig. 3. Evening ion density variations from RPA onboard DMSP-F13, DMSP-F15 and DEMETER (left to the right), presented in isodensity maps from $\pm 50^{\circ}$ geographic latitude vs. $0^{\circ} \div 360^{\circ}$ geographic longitude. From top to the bottom of each column, four panels of total ion density $\mathrm{Ni}, n\left[\mathrm{O}^{+}\right], n\left[\mathrm{H}^{+}\right]$and $n\left[\mathrm{He}^{+}\right]$variations, are shown. The solid black line depicts the location of the geomagnetic equator. Thin black contours correspond to 50 density levels of logarithmic color bar given at the right side of figure.

throughout all evening local times in $\mathrm{Ni}, n\left[\mathrm{O}^{+}\right]$and $n\left[\mathrm{H}^{+}\right]$. Local maxima and minima in $\mathrm{Ni}$ are located at the magnetic equator, within $\pm 15^{\circ}$ MLat and are out of phase with the same features seen in the latter morning hours in Fig. 1. WN4 wave peaks in $\mathrm{O}^{+}$are shifted slightly away from the geomagnetic equator, southward in longitudinal zones with largest positive declination $\left(170^{\circ} \div 260^{\circ}\right)$ and northward in longitudinal zones with largest negative declinations $\left(330^{\circ} \div 350^{\circ}\right)$. This coherent longitudinal behavior of the $\mathrm{O}^{+}$and $\mathrm{H}^{+}$ion densities can be observed up to 21:30 LT.

After sunset the $\mathrm{H}^{+}$density decreases rapidly and by 22:30 LT at $730 \mathrm{~km}$ altitude the density falls below the detection threshold. In both hemispheres, $\mathrm{H}^{+}$density shows an abrupt drop at auroral latitudes, which denotes the average plasmasphere boundary position at these altitudes. The $\mathrm{He}^{+}$ density exceeds $10 \%$ of $\mathrm{H}^{+}$near sunset and slowly decreases towards midnight. These minor species, is most strongly influences by field-aligned plasma transport and shows weakly defined peaks displaced from the magnetic equator in the opposite sense to that seen in the $\mathrm{O}^{+}$ions. Due to the downward vertical drift after sunset and the lack of diffusion from higher altitudes, $\mathrm{He}^{+}$forms a so-called equatorial helium trough at the geomagnetic equator.
On a larger global scale the latitude and longitude distributions of $\mathrm{Ni}$ and $n\left[\mathrm{O}^{+}\right]$, show an enhancement in the region with positive magnetic declinations between $160^{\circ} \div 270^{\circ}$ geographic longitude in the Southern Hemisphere and in the region with negative magnetic declinations between $280^{\circ} \div$ $330^{\circ}$ geographic longitude in the Northern Hemisphere. The enhancements are accompanied by density reductions in the conjugate hemisphere. These features appear as a result of upward/downward field-aligned motions of ions induced by the eastward F-region zonal wind and the magnetic declination ( $\mathrm{Su}$ et al., 2005). This general longitudinal behavior persists into the pre-midnight hours in DEMETER data at $730 \mathrm{~km}$ altitude (Fig. 3). This larger scale motion of the plasma also causes the WN4 features between $\sim 290^{\circ}$ and $\sim 360^{\circ}$ longitude, to merge into an elongated zone of density maximum northward of the geomagnetic equator (panels e, $f$, $i, j)$. Note, however that the longitude extent over which negative declination effects are produced $\left(290^{\circ} \div 360^{\circ}\right)$ is comparable to or less than the peak separations identifying the WN4 variation. Thus our functional fitting process is not optimized to separate these effects in the longitude region. The density deviations characterizing WN4 structures throughout evening hours are shown as function of latitude and longitude on Fig. 4. Daytime $\delta \mathrm{Ni}$ wave amplitudes shown in panel (a) 


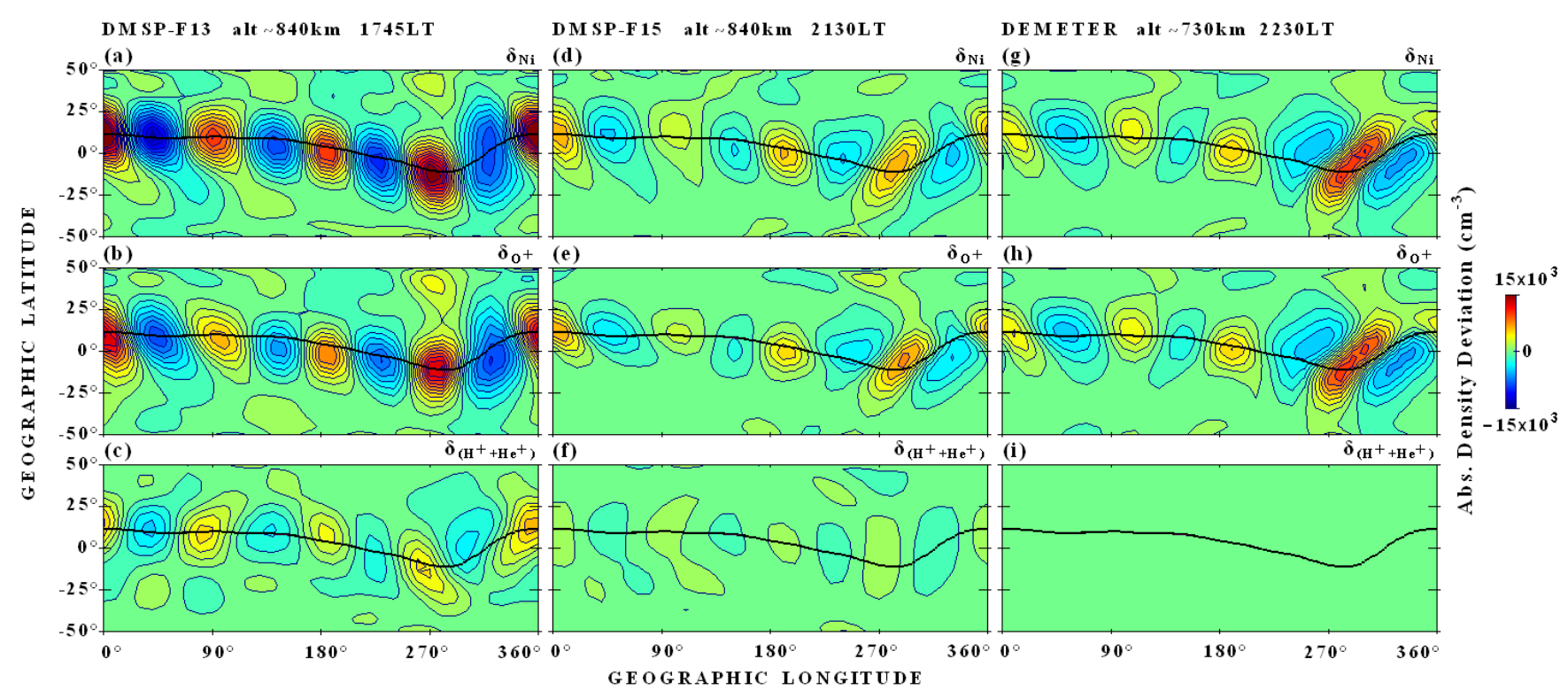

Fig. 4. Evening WN4 density deviation maps from DMSP-F13, DMSP-F15 and DEMETER (left to the right) within $\pm 50^{\circ}$ geographic latitude vs. $0^{\circ} \div 360^{\circ}$ geographic longitude, are shown. From top to the bottom of each column, $\delta \mathrm{Ni}, \delta \mathrm{O}^{+}$and $\delta\left(\mathrm{H}^{+}+\mathrm{He}^{+}\right)$variations are given. Thin black contours of 25 deviation levels correspond to the linear color bar given at the right side, within the range $-15.10^{3} \mathrm{~cm}^{-3}$ to $15.10^{3} \mathrm{~cm}^{-3}$.

of Fig. 4, are comparable to $\delta \mathrm{Ni}$ peak to peak amplitudes at 10:30 LT as seen from DEMETER at $730 \mathrm{~km}$ height (Fig. 2) but out of phase by 180 degrees as mentioned previously. $\mathrm{H}^{+}$ becomes a significant fraction of the total density only near sunset and at that time the WN4 signature mimics that seen in the $\mathrm{O}^{+}$. At $730 \mathrm{~km}$ the $\mathrm{WN} 4$ structures are larger in spatial extent representing their extension along geomagnetic field lines to lower altitudes.

\section{Discussion}

In this study we have described the important features of the ion density distribution in the topside ionosphere that can be summarized as follows:

1. A prominent $\mathrm{WN} 4$ signature can be seen in the $\mathrm{O}^{+}$density distribution at all local times except pre-sunrise.

2. DMSP-F13 pre-sunrise data show very weak WN4 structures in $\mathrm{O}^{+}$with a tendency for the $\mathrm{H}^{+}$distribution to behave in anti-phase with the $\mathrm{O}^{+}$.

3. After sunrise, WN4 wave amplitudes in $\mathrm{Ni}$ and $\mathrm{O}^{+}$ rapidly increase toward daytime and the relative contribution of light ions to WN4 decreases significantly in comparison to $\mathrm{O}^{+}$.

4. The maximum WN4 signature in $\mathrm{O}^{+}$and $\mathrm{H}^{+}$appears in the pre-sunset hours (DMSP-F13) with in-phase behavior in all ion constituents.
5. The latitude position of WN4 peaks deviates significantly from the geomagnetic equator, toward mid latitudes, depending on the sign of the magnetic declination. The latitude offset is northward by day and southward at night for positive magnetic declinations $\left(120^{\circ} \div 280^{\circ}\right)$ and southward by day and northward at night for negative magnetic declinations $\left(330^{\circ} \div 80^{\circ}\right)$.

6. At lower altitudes ( $~ 730 \mathrm{~km}$ DEMETER observations), WN4 wave crests in $\mathrm{Ni}$ and $\mathrm{O}^{+}$density are greater in amplitude with smaller latitude shifts than at higher altitudes ( $\sim 840 \mathrm{~km}$ DMSP), but they retain the same longitudinal behavior.

7. After sunset the absolute magnitude of WN4 signatures decreases rapidly

8. All WN4 signatures are embedded in a larger scale longitude distribution of the ions that is controlled by the magnetic declination and extends beyond the magnetic equator.

It is evident that both $\boldsymbol{E} \times \boldsymbol{B}$ drift perpendicular to the magnetic field and neutral wind induced transport parallel to the magnetic field play a role in the observed ion density distributions in the topside ionosphere. Strong evidence exists here and in previous experimental and theoretical works that WN4 signatures result from a longitudinal modulation in the $\boldsymbol{E} \times \boldsymbol{B}$ drift (Lühr et al., 2008; England et al., 2008; Jin et al., 2008). In the pre-noon hours the prominent WN4 peaks and troughs are 180 degrees out of phase with those seen just 
(a) Morning case

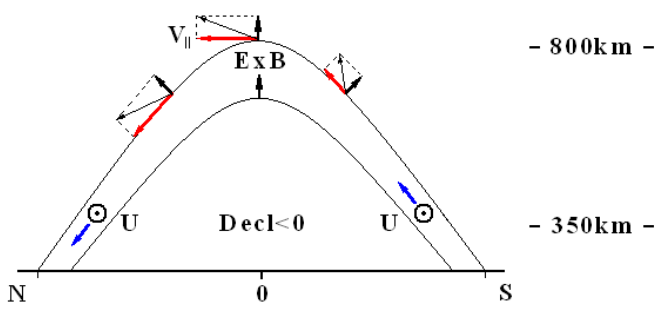

(b) Evening case

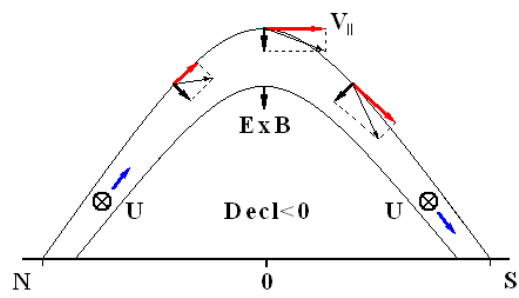

Fig. 5. Topside F-region plasma dynamics induced by $\boldsymbol{E} \times \boldsymbol{B}$ difts and neutral winds. Field-aligned motions (red arrows) are produced by the combined effects of $\boldsymbol{E} \times \boldsymbol{B}$ drifts (thick black arrows) and neutral winds in the meridian (blue arrows). Combined with field-aligned diffusion, the net plasma flow (thin black arrows) produces asymmetries in the ion density.

prior to sunset. AT sunset the WN4 signature in the topside is a maximum and the phase of the peaks and troughs are subsequently retained throughout the night and though significantly weakened they are preserved into the pre-sunrise hours. This suggests that the WN4 variations are driven during the daytime but may be a fossil of the distribution created by the $\boldsymbol{E} \times \boldsymbol{B}$ drift during the daytime. Thus, the driver is weak or absent in the nighttime. (England et al., 2008). The WN4 features are displaced from the magnetic equator and embedded in a weaker larger scale longitude variation produced by F-region zonal winds. These winds have a finite component in the magnetic meridian plane in regions of non-zero declination and induce field-aligned transport in the topside by changing the F-peak height (Heelis and Hanson, 1980; Bailey et al., 2000; Su et al., 2005).

In Fig. 5, a simple sketch illustrates the relevant neutral winds in the $\mathrm{F}$ region and topside equatorial plasma dynamics that produces both the morning and evening WN4 behavior exhibited in our data. For simplicity, only the case of negative magnetic declination $(D<0)$ is shown. In the same manner, a positive declination effect reverses the wind component in the magnetic meridian and the induced fieldaligned motions across the magnetic equator. Red arrows depict $V_{\|}$values and direction while thick black arrows represent $V_{\perp}(\boldsymbol{E} \times \boldsymbol{B})$ motion. The thinner black arrows denote the net plasma motion.

The WN4 signature is produced by longitudinal modulations in the daytime upward $\boldsymbol{E} \times \boldsymbol{B}$ drift. In the topside ionosphere this modulation appears as a change in the peak ion density seen at the magnetic equator. In the F-region the modulation appears most prominently in the ionization anomaly peaks that are displaced from the magnetic equator (Immel et al., 2006) but merge to a single peak at the magnetic equator in the topside. Since the $\boldsymbol{E} \times \boldsymbol{B}$ drifts raise and lower the ionospheric layer at the magnetic equator, in the topside ionosphere this modulation is seen as an in-phase increase and decrease in all the ion species. For daytime equinoxial conditions we neglect the effect of Fregion meridional winds but the F-region zonal wind is directed to the west and will have a north to south component in the magnetic meridian in regions of positive declination and a south to north component in the magnetic meridian in regions of negative declination. A wind component toward the magnetic equator will raise the F-layer producing a higher density $\mathrm{F}$ peak at higher altitude, while at the conjugate location the F-layer will be depressed producing a lower density F-peak. This produces an asymmetry in the plasma distribution at a constant altitude in the topside ionosphere with the peak displaced to the upwind side of the magnetic equator. Thus in a region of negative declination we would expect to see the peak density in the topside displaced to the south in the daytime and to the north in the evening as is observed. This large scale F-region wind moves the entire F-region that is itself modulated by the WN4 $\boldsymbol{E} \times \boldsymbol{B}$ drift contribution. Thus the prominent WN4 peaks are displaced from the magnetic equator in addition to the broader maximum in the underlying ionosphere that is organized by magnetic declination due to the action of the zonal neutral wind. During the nighttime we have suggested that the WN4 driver is largely absent. In this case we expect that the previously established WN4 variations will decay throughout the night. First we note that a change in the phase of the WN4 variations between 10:30 LT and 18:00 LT must be actively driven, but they subsequently retain their phase relations and decay throughout the night and into the pre-sunrise hours. But during this time the neutral wind field is reversed and the background $\boldsymbol{E} \times \boldsymbol{B}$ drift is downward (Fejer et al., 1991; Wharton et al., 1984; Liu et al., 2006). A downward $\boldsymbol{E} \times \boldsymbol{B}$ drift acts to remove the ionization anomaly and drive the peak density toward the magnetic equator. Thus in the topside ionosphere we see the WN4 peaks that are closer to the magnetic equator but remain slightly displaced in accord with the zonal neutral wind that is now directed to the east. We also see comparing Fig. If and Fig. 3f that the large-scale variations in the background ionosphere organized by magnetic declination is also reversed due to the change in direction of the neutral wind. This is illustrated more directly in Fig. 6.

Here the top panels (a) and (d) represent the morning and evening $\mathrm{O}^{+}$distributions from previously seen in Fig. If and Fig. 3f. In the middle (b) and (e), the $\mathrm{O}^{+}$density is shown 


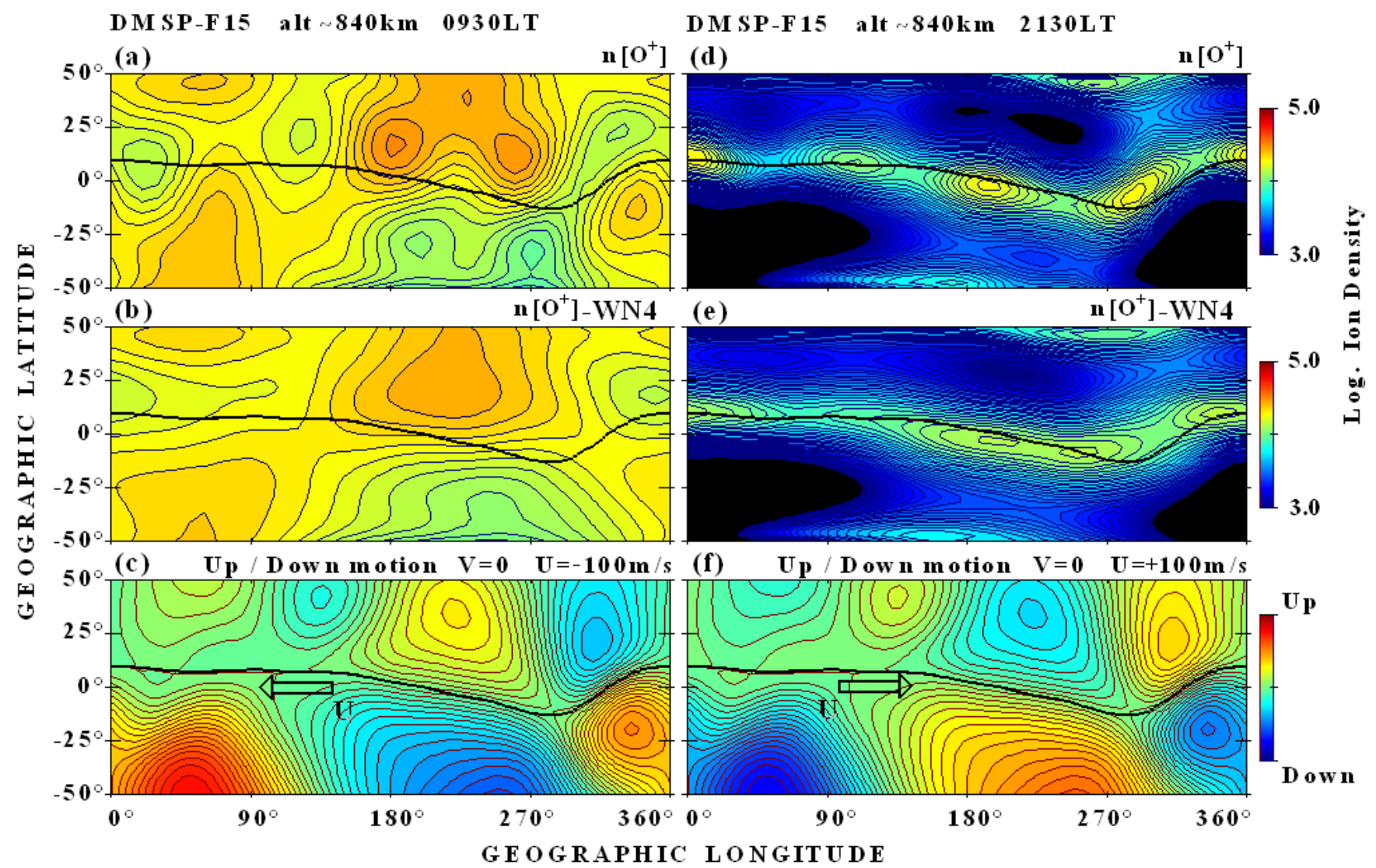

Fig. 6. Morning and evening DMSP-F15 data plots of $n\left[\mathrm{O}^{+}\right]$and $\mathrm{n}\left[\mathrm{O}^{+}\right]-\mathrm{WN} 4$ (panels $\mathbf{a}, \mathbf{b}, \mathbf{d}, \mathbf{e}$ ), combined with calculated vertical wind component induced by constant zonal wind at $350 \mathrm{~km}$ height (panels c, f). Solid black line depicts geomagnetic equator position. Black arrow represents appropriate zonal wind direction.

after the principal WN4 variation is removed from data. The bottom two panels (c) and (f) show the calculated F-region vertical motion at $350 \mathrm{~km}$ resulting from a uniform zonal wind of $100 \mathrm{~m} / \mathrm{s}$ to the west in the morning to the east in the evening local times. The correspondence between $\mathrm{O}^{+}$ density enhancements and depletions with the wind induced upward and downward drifts provides a simple illustration of variable background upon which the WN4 variations are also modulated (Hartman and Heelis, 2007; Kil et al., 2008; Ren et al., 2009; Oh et al., 2008).

Because the background ion drift is downward during the nighttime, processes acting at earlier local times at higher altitudes will influence the observations at a fixed lower altitude. Indeed the observations show this to be the case. During the evening hours at middle latitudes the F-layer decays and the $\mathrm{O}^{+}$density rapidly decreases being modulated in longitude by the zonal wind as noted earlier. The middle latitudes become dominated by $\mathrm{H}^{+}$that diffuses downwards. $\mathrm{He}^{+}$previously produced during the daytime remains suspended above the F-peak at middle latitudes producing a characteristic local maximum in the evening (Gonzalez, 1994). As the $\mathrm{H}^{+}$diffuses downward it will become a larger contributer to the total density in regions where the $\mathrm{O}^{+}$den- sity is smaller. Through most of the night it remains a minor constituent but when it can be identified in the early morning hours (Fig. 1d), the peaks and troughs in $\mathrm{H}^{+}$are in anticoincidence with the peaks and troughs in $\mathrm{O}^{+}$as expected.

\section{Conclusions}

In the present work, it is shown that global scale variations in the topside plasma density have significant latitude and longitude structuring produced by a WN4 variation in the $\boldsymbol{E} \times \boldsymbol{B}$ drift and due to large-scale F-region zonal winds. We suggest that the $\boldsymbol{E} \times \boldsymbol{B}$ driver for the WN4 variations is most active in the daytime and may be absent during nighttime. However, the WN4 variations in ion density and composition once produced, are retained during the night while they decay. Longitude variations driven by F-region winds are present at all local times in the topside ionosphere and modulate the magnitude and location of the peak WN4 variations during the daytime and the nighttime. Here we have exposed the role of a large-scale uniform neutral wind, but the role of wind fields with longitude variations themselves requires further investigation. Further study of intra-annual climatology of 
WN4 density and drift variations in the topside ionosphere is required to reveal both zonal and meridional wind influences on density distributions that display WN4 variations.

Acknowledgements. This work is supported at the University of Texas at Dallas by NASA grants NNX07AF36G, NNX07AT82G and DEMETER-CNES guest investigator program.

Topical Editor K. Kauristie thanks H. Aveiro and another anonymous referee for their help in evaluating this paper.

\section{References}

Bailey, G. J. and Heelis, R. A.: Ion temperature troughs induced by a meridional neutral air wind in the nighttime equatorial topside ionosphere, Planet. Space Sci., 28, 895-907, 1980.

Bailey, G. J., Denton, M. H., Heelis, R. A., and Venkatraman, S.: A modelling study of the latitudinal variations in the nighttime plasma temperatures of the equatorial topside ionosphere during northern winter at solar maximum, Ann. Geophys., 18, 14351446, 2000,

http://www.ann-geophys.net/18/1435/2000/.

Berthelier, J. J., Godefroy, M., Leblanc, F., Seran, E., Peschard, D., Gilbert, P., and Artru, J.: IAP, the thermal plasma analyzer on DEMETER, Planet. Space Sci., 54, 487-501, 2006.

Chandra, S., Troy Jr., B. E., Donley, J. L., and Bourdeau, R. E.: OGO 4 observations of ion composition and temperatures in the topside ionosphere, J. Geophys. Res., 75, 3867-3878, 1970.

Cussac, T., Clair, M.-A., Ultre-Guerard, P., Buisson, F., LassalleBalier, G., Ledu, M., Elisabelar, C., Passot, X., and Rey, N.: The DEMETER microsatellite and ground segment, Planet. Space Sci., 54, 413-427, 2006.

England, S. L., Maus, S., Immel, T. J., and Mende, S. B.: Longitudinal variations of the E-region electric fields caused by atmospheric tides, Geophys. Res. Lett., 33, L21105, doi:10.1029/2006GL027465, 2006.

England, S. L., Immel, T. J., and Huba, J. D.: Modeling the longitudinal variations in the post-sunset far-ultraviolet OI airglow using the SAMI2 model, J. Geophys. Res., 113, A01309, doi:10.1029/2007JA012536, 2008.

Fejer, B. G., dePaula, E. R., Gonzalez, S. A., and Woodman, R. F.: Average vertical and zonal $F$ region plasma drifts over Jicamarca, J. Geophys. Res., 96, 13901-13906, 1991.

Gonzalez, S. A.: Radar, satellite and modeling studies of the low latitude protonosphere, PhD thesis, Utah State Univ., Logan, 1994.

Hagan, M. E., Maute, A., Roble, R. G., Richmond, A .D., Immel, T. J., and England, S. L.: Connections between deep tropical clouds and the Earth's ionosphere, Geophys. Res. Lett., 34, L20109, doi:10.1029/2007GL030142, 2007.

Hanson, W. B., McKibbin, D. D., and Sharp, G. W.: Some ionospheric measurements with a satellite born ion trap, J. Geophys. Res., 69, 1667-1674, 1964.

Hanson, W. B., Sanatani, S., Zuccaro, D., and Flowerday, T. W.: Plasma measurements with the retarding potential analyzer on OGO 6, J. Geophys. Res., 75, 5483-5501, 1970.

Hanson, W. B. and Heelis, R. A.: Techniques for measuring bulk gas motions from satellites, Space Sci. Instrum., 1, 493-524, 1975.
Hartman, W. A. and Heelis, R. A.: Longitudinal variations in the equatorial vertical drift in the topside ionosphere, J. Geophys. Res., 112, A03305, doi:10.1029/2006JA011773, 2007.

Heelis, R. A. and Hanson, W. B.: Interhemispheric transport induced by neutral zonal winds in the F-region, J. Geophys. Res. 85, 3045-3051, 1980.

Heelis, R. A. and Hanson, W. B.: Measurements of thermal ion drift velocity and temperature using planar sensors, in: Measurements Techniques in Space Plasmas: Particles, edited by: Pfaff, R. F., Borovsky, J. E., Yong, D. T., AGU Monograph, 61-71, 1998.

Heelis, R. A.: Electrodynamics in the low and middle latitude ionosphere: a tutorial, J. Atmos. Solar-Terr. Phys., 66, 825-838, 2004.

Henderson, S. B., Swenson, C. M., Christensen, A. B., and Paxton, L. J.: Morphology of the equatorial anomaly and equatorial plasma bubbles using image subspace analysis of Global Ultraviolet Imager data, J. Geophys. Res., 110, A11306, doi:10.1029/2005JA011080, 2005.

Immel, T. J., Sagawa, E., England, S. L., Henderson, S. B., Hagan, M. E., Mende, S. B., Frey, H. U., Swenson, C. M., and Paxton, L. J.: Control of equatorial ionospheric morphology by atmospheric tides, Geophys. Res. Lett., 33, L15108, doi:10.1029/2006GL026161, 2006.

Jin, H., Miyoshi, Y., Fujiwara, H., and Shinagawa, H.: Electrodynamics of the formation of ionospheric wave number 4 longitudinal structure, J. Geophys. Res., 113, A09307, doi:10.1029/2008JA013301, 2008.

Kil, H., DeMajistre, R., Paxton, L. J., and Zhang, Y.: Nighttime F-region morphology in the low and middle latitudes seen from DMSP F15 and TIMED/GUVI, J. Atmos. Solar Terr. Phys., 68, 1672-1681, 2006.

Kil, H., Oh, S.-J., Kelley, M. C., Paxton, L. J., England, S. L., Talaat, E., Min, K.-W., and Su, S.-Y.: Longitudinal structure of the vertical ExB drift and ion density seen from ROCSAT-1, Geophys. Res. Lett., 34, L14110, doi:10.1029/2007GL030018, 2007.

Kil, H., Talaat, E. R., Oh, S.-J., Paxton, L. J., England, S. L., and Su, S.-Y: Wave structures of the plasma density and vertical $\mathbf{E x B}$ drift in low-latitude F region, J. Geophys. Res., 113, A09312, doi:10.1029/2008JA013106, 2008.

Knudsen, W. C.: Evaluation and Demonstration of the use of retarding potential analyzers for measuring several ionospheric quantities, J. Geophys. Res., 71, 4669-4678, 1966.

Lin, C. H., Hsiao, C. C., Liu, J. Y., and Liu, C. H.: Longitudinal structure of the equatorial ionosphere: Time evolution of four-peaked EIA structure, J. Geophys. Res., 112, A12305, doi:10.1029/2007JA012455, 2007.

Liu, H., Lühr, H., Watanabe, S., Köhler, W., Henize, V., and Visser, P.: Zonal wind in the upper atmosphere observed by CHAMP: Climatology, J. Geophys. Res., 111, A07307, doi:10.1029/2005JA011415, 2006.

Lühr, H., Rother, M., Häusler, K., Alken, P., and Maus, S.: The influence of non-migrating tides on the longitudinal variations of the equatorial electrojet, J. Geophys. Res., 113, A08313, doi:10.1029/2008JA013064, 2008.

MacPherson, B., Gonzalez, S. A., Bailey, G. J., Moffett, R. J., and Sulzer, M. P.: The effects of meridional neutral winds on the $\mathrm{O}^{+} \div \mathrm{H}^{+}$transition altitude over Arecibo, J. Geophys. Res., 103(A12), 29183-29198, 1998.

Oberheide, J. and Forbes, J. M.: Tidal propagation of 
deep tropical cloud signatures into the thermosphere from TIMED observations, Geophys. Res. Lett., 35, L04816, doi:10.1029/2007GL032397, 2008.

Oh, S.-J., Kil, H., Kim, W.-T., Paxton, L. J., and Kim, Y. H.: The role of the vertical $\boldsymbol{E} \times \boldsymbol{B}$ drift for the formation of the longitudinal plasma density structure in the low-latitude F region, Ann. Geophys., 26, 2061-2067, 2008, http://www.ann-geophys.net/26/2061/2008/.

Pedatella, N. M., Forbes, J. M., and Oberheide, J.: Intra-annual variability of the low-latitude ionosphere due to non-migrating tides, J. Geophys. Res., 35, L18104, doi:10.1029/2008GL035332, 2008.

Ren, Z., Wan, W., Liu, L., Wei, Y., Yue, X., and Heelis, R. A.: Longitudinal variations of electron temperature and total ion density in the sunset equatorial topside ionosphere, Geophys. Res. Lett., 35, L05108, doi:10.1029/2007GL032998, 2008.

Ren, Z., Wan, W., Liu, L., and Xiong, J.: Intra-annual variations of wave number- 4 structure of vertical ExB drifts in the equatorial ionosphere seen from ROCSAT-1, J. Geophys. Res., 114, A05308, doi:10.1029/2009JA014060, 2009.

Rishbeth, H.: The equatorial F-layer: progress and puzzles, Ann. Geophys., 18, 730-739, 2000, http://www.ann-geophys.net/18/730/2000/.
Sagawa, E., Immel, T. J., Frey, H. U., and Mende, S. B.: Longitudinal structure of the equatorial anomaly in the nighttime ionosphere observed by IMAGE/FUV, J. Geophys. Res., 110, A11302, doi:10.1029/2004JA010848, 2005.

Sherliess, L., Thompson, D. C., and Schunk, R. W.: Longitudinal variability of low-latitude total electron content: Tidal influences., J. Geophys. Res., 113, A01311, doi:10.1029/2007JA012480, 2008.

Su, S.-Y., Chao, C. K., Yeh, H. C., and Heelis, R. A.: Seasonal and latitudinal distributions of the dominant light ions at $600 \mathrm{~km}$ topside ionosphere from 1999 to 2002, J. Geophys. Res., 110, A01302, doi:10.1029/2004JA010564, 2005.

Wan, W., Liu, L., Pi, X., Zhang, M.-L., Ning, B., Xiong, J., and Ding, F.: Wavenumber-4 patterns of the total electron content over the low latitude ionosphere, Geophys. Res. Lett., 35, L12104, doi:10.1029/2008GL033755, 2008.

West, K. H. and Heelis, R. A.: Longitude variations in ion composition in the morning and evening topside ionosphere near solar minimum, J. Geophys. Res., 101, 7951-7960, 1996.

Wharton, L., Spenser, N., and Meyer, H.: The Earth's super-rotation from Dynamics Explorer 2, Geophys. Res. Lett., 11, 531-533, 1984. 